COST OF NEONatal SURvivorship: Deuglas $D$. Deming, $43 \frac{N i d i a}{2}$ Vyhmeister. Susan I. Neese. (Spon by J. Joseph Quilligan) Loma Linda

Medicine, Dept of Pediatrics, Loma Linda, CA dramatic increase During the last few years there has been a dramatic increase in medical costs and the number of survivors of neonatal survivors from NICU's has decreased with the increase number of survivors
survivors.

survivors. the Loma Linda Univ NICU between Jan 1981 and June 1983. The charges were analyzed in various groups by gestational age, birthweight, and diagnositic categories. A cost of survivorship (COS) was calculated by dividing the total charges for each group of infants by the number of survivors in that group. Additionally we looked at the length of stay and the number of admissions and survivors in each category.

The cos for infants with birthweights greater than $1000 \mathrm{gms}$ did not change during the study [ $\$ 26144(1981)$ to $\$ 26745(1983)$, calculated using the local medical inflation rate]. For infants less than $1000 \mathrm{gms}$ the $\cos$ increased if less than $50 \%$ of the category survived, but the $\cos$ decreased if the survivors were greater than $50 \%$ of their category [ $\$ 242617,2$ surv/21 babies greater than $50 \%$ of their category [\$2 16 surv/27 babies(1982)]. The infants who survived had a longer hospital stay and a greater cost than those who died.

We conclude that the $\cos$ is dependent on an absolute increase in the number of survivors, the length of hospital stay, and the percent of infants surviving in each category.

NEONATAL MORTALITY RISK OF SICK PREMATURE INFANTS IN

44 AN OUTBORN POPULATION. Delphine Eichorst, M.D.;

M.D., all of The ChiT $\frac{\text { Q }}{\text { ren's Hospital, Denver, Colorado }}$

Neonatal mortality of all patients $<37$ weeks gestation transported to The Children's Hospital Denver tertiary care nursery ported to The Children's Hospital Denver tertiary care nursery

$<37$ weeks gestation and 280 neonatal deaths (mortality $14.2 \%$ ). lar to that recently published by the University of colorado.

Neonatal Mortality $\%$

Gestation (wks) 1978-82 TCH(outborn) UCHSC(īnborn) 1974-80

26-31 AGA

26-31 AGA

26-33 SGA

34-36 AGA

$34-36$ SGA

52
16
$34-49$
8
$2-4$
8

20

$39-63$

$0.2-2$

Improved mortality for the extremely low birthweight category in the outborn population probably reflects transport of only the most vigorous infants. For the larger outborn premature infants, the increased mortality probably reflects the severity of illness of these babies and the greater number of weli infants in the inborn population. We feel that the survival in our outborn inborn population. We feel that the survival in our outborn
population is comparable. This is significant considering the population is comparable. This is significant cons
long distance many of our infants are transported.

This mortality risk chart for sick premature infants may be helpful to referring physicians and to families of these transported infants.

SOCIAL ENVIRONMENT AND DEVELOPMENT IN HIGH RISK

45 INFANTS. Stephen C. Engelke, Ken Aung-Din and Evelyn Sanders (Spon. by Jean Kenny). East Carol ina Univ. School of Medicine, Dept. of Pediatrics, Greenville, NC.

The importance of social environment on infant development was prospectively studied. Social worker assessment (SWA) and a psychosocial inventory (PSI) were administered before discharge to mothers of 138 ill newborns: 93 patients with no neurological disorder (group I) and 45 with intraventricular hemorrhage (group II). The PSI included a summary psychosocial score (PSS) and subscores measuring stress, support systems, parenting andils, psychological profile, child abuse potential (CAP) and pregnancy attitudes (PA) (Altemeier 1979, others). Testing was done at 6,12 and 18 months of age. Abnormal neurodevelopment was defined as Bayley indices $<69$, failure on Denver Development testing or major neurological abnormality.

In both groups I and II, abnormal SWA (Ia, IIa) had an additive effect compared to normal SWA (In, IIn) on risk of abnormal development (\%): $12 \%$ (In), $28 \%$ (Ia), $50 \%$ (IIn), $64 \%$ (IIa), p<.001. PSI scores were higher in group I with normal versus abnormal

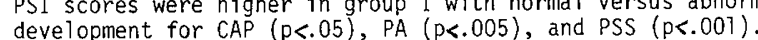
PSS significantly correlated with iater neurodevelopment:

$$
\begin{array}{lcccc}
P S S \leq 0 & \frac{\text { Normal }}{19} & \frac{\text { Abnorma }}{14} & \frac{(\%) \text { abnormal }}{42 \%} & \frac{p}{<.001} \\
P S S>0 & 54 & 6 & 10 \% & <.001
\end{array}
$$

Differences remained, controlling income and mother's education.

A relationship is shown between social environment at birth and subsequent development which may allow earlier prediction and help for families of neonates at high risk of abnormal outcome.
DECREASED CIRCUMCISION RATE WITH VIDEOTAPE COUNSEL-

46 LING. Robert W.Enzenauer, Tom E.Wiswell, John M. powe11, James W. Bass, (Spon. by James W.Bass, Tripler Army Medical Center, Dept. of Pediatrics, Honolulu, HI.

Most parents are not properly counselled about neonatal circumcision. We hypothesized that counselling using videotape presentations might be effective in reducing the circumcision frequency rate (CFR). We perforned an intervention trial to test this hypothesis. A videotape presentation summarizing factors relating to neonatal circumcision was prepared. Permission was obtained from NBC, Inc. to also present Kiker's NBC News Magazine commentary "Circumcision: the casual cut" which aired in Nov 1981. In the videotape counsel group (VTCG), parents of male infants born between 1 Jan and 30 Jun 1982 were asked to view the two videotapes before deciding for or against circumcision. In the routine physician counsel group (RPCG), parents of male infants born after 1 Ju1 1982 were counselled by the house officer-on-call without the videotape. This second method of counselling was what had been practiced prior to undertaking the study. The CFR of the VTCG was compared to the RPCG and with circumcision data from previous years at Tripler AMC. Results are as follows:

\begin{tabular}{|c|c|c|c|c|c|}
\hline \multicolumn{5}{|c|}{ UNSELLING } & \multirow{2}{*}{$\begin{array}{l}\text { Conclusion: VTC is an } \\
\text { effective method for }\end{array}$} \\
\hline & $\begin{array}{l}\text { MONTH/ } \\
\text { YEAR }\end{array}$ & $\begin{array}{l}\text { MALE } \\
\text { BIRTHS }\end{array}$ & $\begin{array}{l}\text { MALE } \\
\text { CIRC.'S }\end{array}$ & & \\
\hline & $1973-1981$ & 15,904 & 14,370 & $90.0 \%$ & circumcision, and sig- \\
\hline & & & & & \\
\hline & & & & $72.5-5+x-200$ & \\
\hline & $\begin{array}{ll}\text { Oct-Dec } 82 \\
\text { Jan-Ji } 83\end{array}$ & $\begin{array}{l}404 \\
805\end{array}$ & $\begin{array}{l}322 \\
6 \times 6\end{array}$ & $\begin{array}{l}79.7 \% \\
84.0 \%\end{array}$ & $(\mathrm{p}<.05)$. \\
\hline
\end{tabular}

PARENTAL NEEDS IN A NBONATAL INTENSIVE CARE
FOLLOW-UP CLINIC. Victor Fornari, Miriam

47 Sherman, and Eveiyn Liloper, (Spon, by Peter Center, New Hyde Park, N.Y. Department of Child Psychiatry and Cormell Medical College, The New York Hospital Depa

Pediatric Mental Health and Perinatology, New York.
There has been a recent increase in the number of neonatal intensive care units. The literature suggests that premature innfants are poorly parented more frequently than full term infants. It is known that low birth weight and seriously ill infants have a higher incidence of abuse and
failure-to-thrive than those born at full tem. In order to failure-to-thrive than those born at full tem. In order
provide optimal care for parents of high risk infants an attempt was made to assess what these parents perceived their needs to be. They were offered an opportunity to be a part of basis.

Sixty-one parents of infants from age 1-18 months were evaluated using a brief semi-structured interview. Results indicated that 628 of parents interviewed wanted the intervention program. A discriminant analysis was performed to detemine what variables correlated with the parents desire to engage in the intervention program.

Higher socio-economic status (SES) and greater severity of illness were directly correlated with parents wanting an intervention. Younger maternal age and lower SES were correlated with not wanting the intervention program.
programs designed to meet the needs of these parents should be Programs designed to meet the needs of these parents should be
part of the commprehensive care prescription. Other programs must be designed to reach the low SES young mother.

\section{$\dagger 48$}

EFFECTS OF CHRONIC HEALTH CONDITIONS ON SCHOOL ADAP48 by Frank Loda). INTC Dept. of Peds., Chape1 Hi11, NC This study of children with chronic health conditions (CHC) assessed the relationship of demographic and health variables to school achievement and absenteeism. From July 1982 to June 1983 data were collected in 11 subspeciality clinics on 270 children followed at a tertiary care center. Academic performance and days absent for the prior year were obtained from schools. Physicians rated subjects' activity limitation. The $\mathrm{CHC}$ group was $61 \%$ male, $68 \%$ white, mean age 12 years. Children with cystic fibrosis, arthritis, sickle cell disease, hemophilia, and spina bifida averaged the most days absent $(>20)$, while those with chronic lung and cardiac conditions averaged the least (10). Total $\mathrm{CHC}$ achievement scores were well below the state average (53rd vs. 63rd percentile). Group scores were highest for general hematology, hemophilia, chronic bowe1 and lung. Scores were lowest for epilepsy (39th), sickle cell (24th), and spina bifida (21st), and these groups had the highest rates of repeatec grades and special services. Overall CHC group achievement was unrelated to school absence. A stepwise regression model related demographic and health variables to $10 \mathrm{~g}$ of days absent and achievement scores. Achievement was correlated with socioeconomic status, race, grade failure, and type of $\mathrm{CHC}\left(\mathrm{r}^{2}=.44 ; \mathrm{p}=.0001\right)$ while school absence was mininly related to health variables (activity limitation, number of clinic "isits, specific CHC) and female sex ( $\mathrm{r}^{2}=.17$; $\mathrm{p}=$ .0001). For CHC children, demographic factors were important predictors of academic performance. CHC children of low socioeconomic status were at double jeopardy for poor school achievement. 